九州大学学術情報リポジトリ

Kyushu University Institutional Repository

\title{
Optimization of Drying Condition for Brown Rice with Low Moisture Content
}

Genkawa, Takuma

Faculty of Agriculture, Kyushu University

Inoue, Asako

Faculty of Agriculture, Kyushu University

Uchino, Toshitaka

Faculty of Agriculture, Kyushu University

Tanaka, Fumihiko

Faculty of Agriculture, Kyushu University

他

https://doi.org/10.5109/9347

出版情報：九州大学大学院農学研究院紀要. 52 (2)，pp. 381-385，2007-10-29. Faculty of Agriculture, Kyushu University

バージョン :

権利関係 : 


\title{
Optimization of Drying Condition for Brown Rice with Low Moisture Content

\author{
Takuma GENKAWA ${ }^{1}$, Asako INOUE ${ }^{1}$, Toshitaka UCHINO*, Fumihiko TANAKA \\ and Daisuke HAMANAKA
}

\author{
Laboratory of Postharvest Science, Division of Bioproduction System Sciences, Department of \\ Bioproduction Environmental Sciences, Faculty of Agriculture, Kyushu University, \\ Fukuoka 812-8581, Japan \\ (Received June 30, 2007 and accepted July 17, 2007)
}

\begin{abstract}
Optimal drying condition of brown rice was discussed for the low-moisture-content storage. A $100 \mathrm{~g}$ of brown rice samples with $15.5 \%$ moisture content wet basis (m.c.) was dried to $10.0 \%$ m.c. at 40, 50, 60, and $70^{\circ} \mathrm{C}$ by thin-layer drying. The germination rate of the brown rice dried at $70^{\circ} \mathrm{C}$ decreased, and drying operation did not affect the germination rate of the rice dried at $40-60^{\circ} \mathrm{C}$. In addition, we discussed changes in cracking rate of brown rice after drying. Regardless of drying temperature, the cracking rate was less than $1 \%$ soon after drying. The cracking rate, however, changed with the passage of time, and depends on drying temperature; the rice dried at $30^{\circ} \mathrm{C}$ has less than $1 \%$ of cracking rate after 72 hours, the cracking rate of the rice dried at 50 and $60^{\circ} \mathrm{C}$ increased until after 48 hours, and that of the rice dried at $70^{\circ} \mathrm{C}$ continued to increase for 72 hours. Finally, the Effect of drying condition on cracking rate was researched by drying samples at a combination of $30,40,50^{\circ} \mathrm{C}$ and $5-10,15-20,25-30 \%$ of relative humidity $(\mathrm{RH})$. From the results, it was suggested that drying temperature more affected the cracking rate than relative humidity in drying brown rice with $15.5 \%$ m.c. This suggestion was confirmed by multiple linear regression analysis. The optimal condition for drying brown rice from 15 to $10 \%$ m.c. was $40{ }^{\circ} \mathrm{C}$ and 5-20\% RH from the viewing point of keeping rice quality and decreasing drying time.
\end{abstract}

\section{INTRODUCTION}

In Japan, brown rice is stored at a low temperature to keep its quality and to prevent microbial deteriorations. The low-temperature storage, however, has never been popular on a worldwide because of problems on const. Therefore, it is necessary to develop storage alternatives without a refrigerator, which have same storability as the low-temperature storage.

Against this, we proposed an alternative storage method of the low-moisture-content storage (Genkawa et al., 2006). To obtain a high storability, rice is dried to $10 \%$ of moisture content on wet basis (m.c.), with which metabolisms of rice are depressed even at room temperature. This storage method can preserve the brown rice without the refrigeration as well as the low-temperature storage. However, there is a problem on cost for drying operation. Additional energy is needed for drying rice from 15 to $10 \%$ m.c. and is larger than that from 20 to $15 \%$ m.c. because the evaporative latent heat increases with decreasing moisture content.

In order to solve this problem, the brown rice is dried from 15 to $10 \%$ m.c. Rough rice is usually dried from moisture content at harvesting, more than 20\% m.c., to the final moisture content for storage of $15 \%$ m.c., but the energy for drying hull is waste and increases the cost of drying. The drying brown rice technique can decrease the energy for drying hull which prevents water evaporation from rice in drying

${ }^{1}$ Laboratory of Postharvest Science, Division of Bioproduction System Sciences, Department of Bioproduction Environmental Sciences, Graduate School of Bioresource and Bioenvironmental Sciences, Kyushu University

* Corresponding author (E-mail: toshiu@bpes.kyushu-u.ac.jp)
(Yamashita et al., 1989). Cracked rice is produced by drying brown rice more than by drying rough rice (Yamashita et al., 1989), but this problem can be solved by using the tempering drying technique. At first, rough rice is dried to $15 \%$ m.c., and after husking, brown rice is dried again to $10 \%$ m.c. Goto et al. (1994) reported that the cracking rate after drying brown rice decreased with decreasing initial moisture content. Therefore, it is expected that the cracked rice is reduced by drying brown rice from $15 \%$ m.c. which is very low as a initial moisture content.

In this study, brown rice was dried from 15 to $10 \%$ m.c. under various condition of temperature and relative humidity. From the results obtained, we discussed the optimal drying condition of brown rice taking germination rate and cracking rate into consideration.

\section{MATERIALS AND METHODS}

\section{Preparation of samples}

Rice (Oryza sativa L., cultivars 'Hinohikari') harvested in Kyushu University Farm in October 2004 was tested. The moisture content of rough rice was approximately $21 \%$ on wet basis (w.b.) at harvest time, and the rice was dried to $15.5 \%$ m.c. at $42-45^{\circ} \mathrm{C}$. After drying, the rice was husked and stored in an airtight container at $5^{\circ} \mathrm{C}$ until use. Damaged rice including cracked rice was removed before examination with a rice quality inspector (SATAKE, RGQI-20A). This device is capable of inspecting brown rice for damage, removing the damaged rice, and counting the number of cracked rice.

\section{Experimental apparatus}

Schematic diagram of experimental apparatus for rice drying is shown in Fig. 1. A drying device equipped 
with a fan (Fig. 2.) was put into a constant temperature oven (Yamato Scientific, DK-63), and a humidifier (Mitsubishi Electric, SV-H604) was connected to the oven. Temperature and relative humidity of drying air were measured with a thermocouple and a humidity sensor (Hioki E. E., 9681) at suction opening of the drying device, and logged on a data logger (Hioki E. E., Memory Hilogger, 8421-51) every 5 minutes.

The drying device consisted of a body part and a drying part. The body part was made of a fan and a polyvinyl-chloride pipe with $83 \mathrm{~mm}$ of inside diameter and $3 \mathrm{~mm}$ of wall thickness. The drying part was the polyvinyl-chloride pipe with a metal screen $(2 \mathrm{~mm}$ mesh). Drying air flowed from bottom into drying part, and the ratio of air rate to grain weight at the drying part was $8.12 \times 10^{-3} \mathrm{~m}^{3} / \mathrm{s}$ per $100 \mathrm{~g}$, which is sufficient for thin layer drying condition.

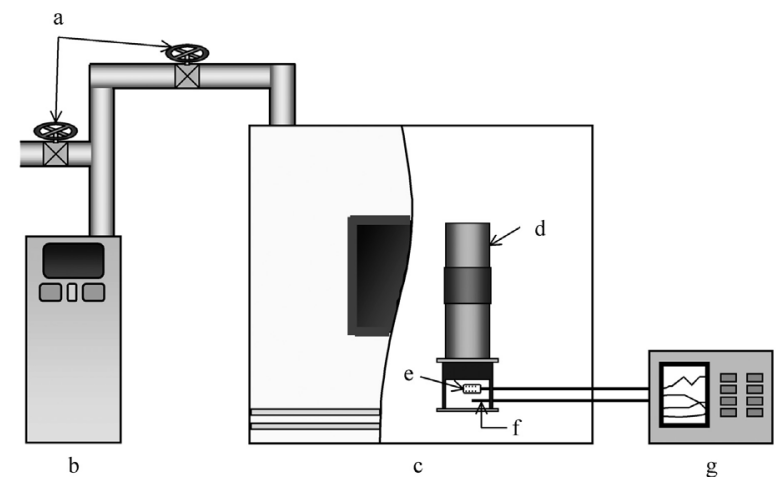

a: control valve, b: humidifier, c: constant temperature oven, d: drying device, e: humidity sensor, f: T-type thermocouple, g: data logger.

Fig. 1. Schematic diagram of experimental apparatus for rice drying.
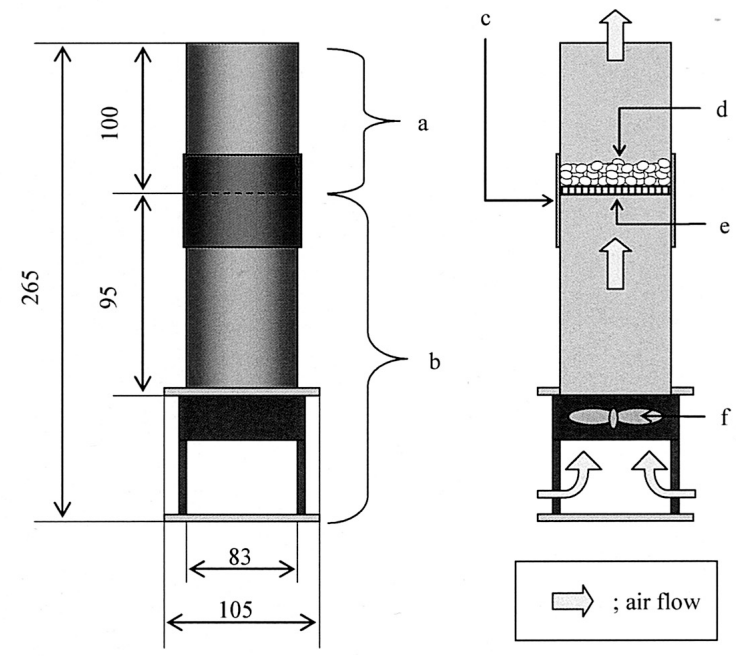

a: drying part, b: body part, c: connection, d: brown rice, e: metal screen, f: fan.

Fig. 2. Detail drawing of drying device with forced ventilator. (unit : $\mathrm{mm}$ )

\section{Experimental methods}

At first, to clarify an effect of drying temperature on germinability of brown rice, we dried a $100 \mathrm{~g}$ of the rice from 15.5 to $10.0 \%$ m.c. at $40,50,60$, and $70^{\circ} \mathrm{C}$ with the drying device, and the germination rate was measured after drying. The moisture content of $15.5 \%$ w.b. was considered as a control. Student's t-test $(p<0.05)$ was performed for estimating the effect of drying temperature on germination rate. To determine the germination rate, 100 kernels of whole brown rice were decontaminated with sodium hypochlorite solution and a wet paper put in a Petri dish. The Petri dishes were placed into an incubator set at $20^{\circ} \mathrm{C}$ and the ratio of germinated grains was counted after 7 days.

Secondly, we determined the time at which the cracking rate should be measured in this study. It is known that even if there is no cracked rice soon after drying, the cracking rate increases with the elapsed time after drying (Yamaguchi et al., 1980). In order to know the optimum time for measuring cracking, the time at which cracking rate would saturate was evaluated. A $100 \mathrm{~g}$ of brown rice was dried from 15.5 to $10.0 \%$ m.c. at $40,50,60$, and $70^{\circ} \mathrm{C}$, and cracking rate was measured after $0,24,48$, and 72 hours by the rice quality inspector described above. Table 1 shows the drying condition of this experiment.

Table 1. Drying condition of experiment

\begin{tabular}{cccc}
\hline $\begin{array}{c}\text { Temperature } \\
\left({ }^{\circ} \mathrm{C}\right)\end{array}$ & $\begin{array}{c}\text { Relative } \\
\text { humidity } \\
(\%)\end{array}$ & $\begin{array}{c}\text { Grain } \\
\text { temperature } \\
\left({ }^{\circ} \mathrm{C}\right)\end{array}$ & $\begin{array}{c}\text { Drying } \\
\text { time } \\
(\mathrm{h})\end{array}$ \\
\hline 40 & 17.8 & 35.9 & 8 \\
50 & 10.9 & 42.2 & 5 \\
60 & 7.6 & 48.3 & 3 \\
70 & 4.9 & 55.7 & 2 \\
\hline
\end{tabular}

Finally, we analyzed drying characteristics of brown rice (100 g) during drying from 15.5 to $10.0 \%$ m.c. under drying conditions of 3 levels of temperature and 3 levels of relative humidity shown in Table 2 , and the cracking rate was measured with the rice quality inspector at 48 hours after drying. The drying condition of $5-10 \%$ of relative humidity $(\mathrm{RH})$ at $30^{\circ} \mathrm{C}$ was impossible to produce with the experimental apparatus. Initial moisture content of $15.5 \%$ m.c. was measured according to the air-oven method specified by the Japanese Society of Agricultural Machinery (JSAM), i.e. drying $10 \mathrm{~g}$ of whole grain at $135^{\circ} \mathrm{C}$ for 24 hours. The value measured was converted to the value specified by the Japan Food Agency (JFA), i.e. drying $5 \mathrm{~g}$ of crushed sample in an oven set at $105^{\circ} \mathrm{C}$ for 5 hours. The conversion equation is shown as Equation (1).

$$
M_{105}=100-1.0122 \times\left(100-M_{135}\right)
$$

where, $M_{105}$ is the value obtained by JFA method (\% wet basis), $M_{135}$ is the value obtained by JSAM method (\% wet basis). Moisture content during drying operation was calculated from change in sample weight by using 
Table 2. Temperature and relative humidity of drying air

\begin{tabular}{|c|c|c|c|c|c|c|c|c|}
\hline \multirow{2}{*}{$\begin{array}{c}\text { Temperature*, }{ }^{\circ} \mathrm{C} \\
\text { Relative humidity*, \% }\end{array}$} & \multicolumn{2}{|c|}{30} & \multicolumn{3}{|c|}{40} & \multicolumn{3}{|c|}{50} \\
\hline & $15-20$ & $25-30$ & $5-10$ & $15-20$ & $25-30$ & $5-10$ & $15-20$ & $25-30$ \\
\hline Temperature**, ${ }^{\circ} \mathrm{C}$ & 30.6 & 30.1 & 40.1 & 40.5 & 39.9 & 50.2 & 50.0 & 50.0 \\
\hline Relative humidity**, \% & 17.9 & 26.3 & 8.3 & 18.1 & 27.5 & 8.6 & 16.7 & 27.0 \\
\hline Drying time, $\mathrm{h}$ & 9.5 & 14.0 & 3.5 & 4.0 & 6.0 & 2.0 & 2.5 & 3.0 \\
\hline
\end{tabular}

* Preset value

** Average value

Equation (2).

$$
M_{f}=100+\left(M_{i}-100\right) \times W_{i} / W_{f}
$$

where, $M_{f}$ is the moisture content after drying (\% wet basis), $M_{i}$ is the initial moisture content (\% wet basis), $W_{i}$ is the initial weight of sample (g), and $W_{f}$ is the weight of sample after drying (g). The drying part in which sample was set was detached from the drying device and measured its weight with an electronic balance (A and D, FX-400) every hour.

\section{RESULTS AND DISCUSSION}

\section{Effect of drying temperature on germination rate of brown rice}

Figure 3 shows germination rate of brown rice with $10.0 \%$ m.c. dried at various temperatures. The brown rice with $15.5 \%$ m.c. as the control had $95 \%$ of germination rate. There was no significant difference between the control and others dried at $40-60^{\circ} \mathrm{C}$, but the germination rate of brown rice dried at $70^{\circ} \mathrm{C}$ was declined to 70\%. Iwasaki et al. (1967) researched on the effect of heating on interruption of brown rice germinability. They heated brown rice with 15 and $21 \%$ of initial moisture content at $60^{\circ} \mathrm{C}$ for 1 hour, and reported that the degree of interruption of germinability by heating depended on the initial moisture content; the germination rate of brown rice with $15 \%$ m.c. did not decline by heating though that of brown rice with $21 \%$ m.c. declined to $24 \%$. They also suggested that rice increases a heating tolerance with decreasing moisture content.

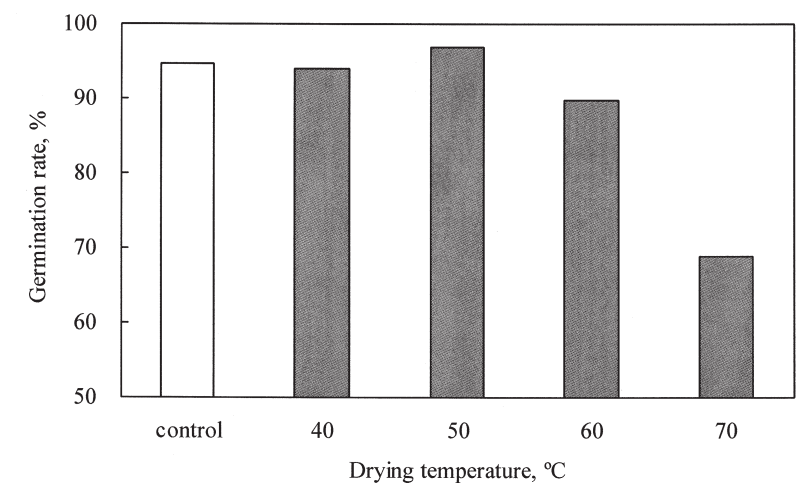

Fig. 3. Germination rate of brown rice with $10.0 \%$ of moisture content dried at various temperatures.
Our results supported their notion because the brown rice with initial moisture content of $15.5 \%$ w.b. kept its germinability after drying at less than $60^{\circ} \mathrm{C}$ for 3 hours.

\section{Time at which cracking rate saturates}

Figure 4 shows changes in cracking rate of brown rice after drying at several temperatures. Regardless of the drying temperature, the brown rice had less than $1 \%$ of cracking rate soon after drying. The cracking rate increased with passage of time and a degree of the increase depended on drying temperature. The rice dried at $40^{\circ} \mathrm{C}$ kept less than $1 \%$ of cracking rate at 72 hours after drying, but the cracking rate of the rice dried at 50 and $60{ }^{\circ} \mathrm{C}$ increased until after 48 hours, and that of the rice dried at $70^{\circ} \mathrm{C}$ continued to increase after 48 hours. From this result, we decided the cracking rate was measured at 48 hours after drying. The cracking rate of brown rice dried at $70^{\circ} \mathrm{C}$ was neglected because the germinability was extremely decreased.

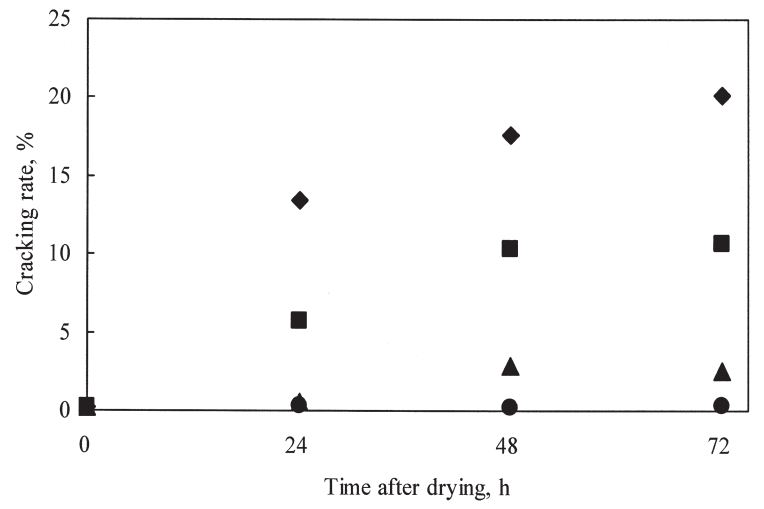

Fig. 4. Changes in cracking rate of brown rice after drying. Symbols of $(\boldsymbol{\nabla}),(\mathbf{\square}),(\mathbf{\Delta})$, and $(\mathbf{)})$ represent the drying temperature of $70,60,50$, and $40^{\circ} \mathrm{C}$, respectively.

\section{Effect of drying condition on drying rate of brown rice}

Changes in moisture content of brown rice in drying operation are shown in Fig. 5. The rice was dried until $10.0 \%$ m.c. under all drying condition tested in this work, but it took longer time to finish drying with decreasing temperature and increasing relative humidity. Figure 6 shows the effect of drying temperature on drying rate of brown rice at $25-30 \% \mathrm{RH}$. Drying rate at 1 hour after initial of drying (initial drying rate, IDR) increased with increasing drying temperature, but there 

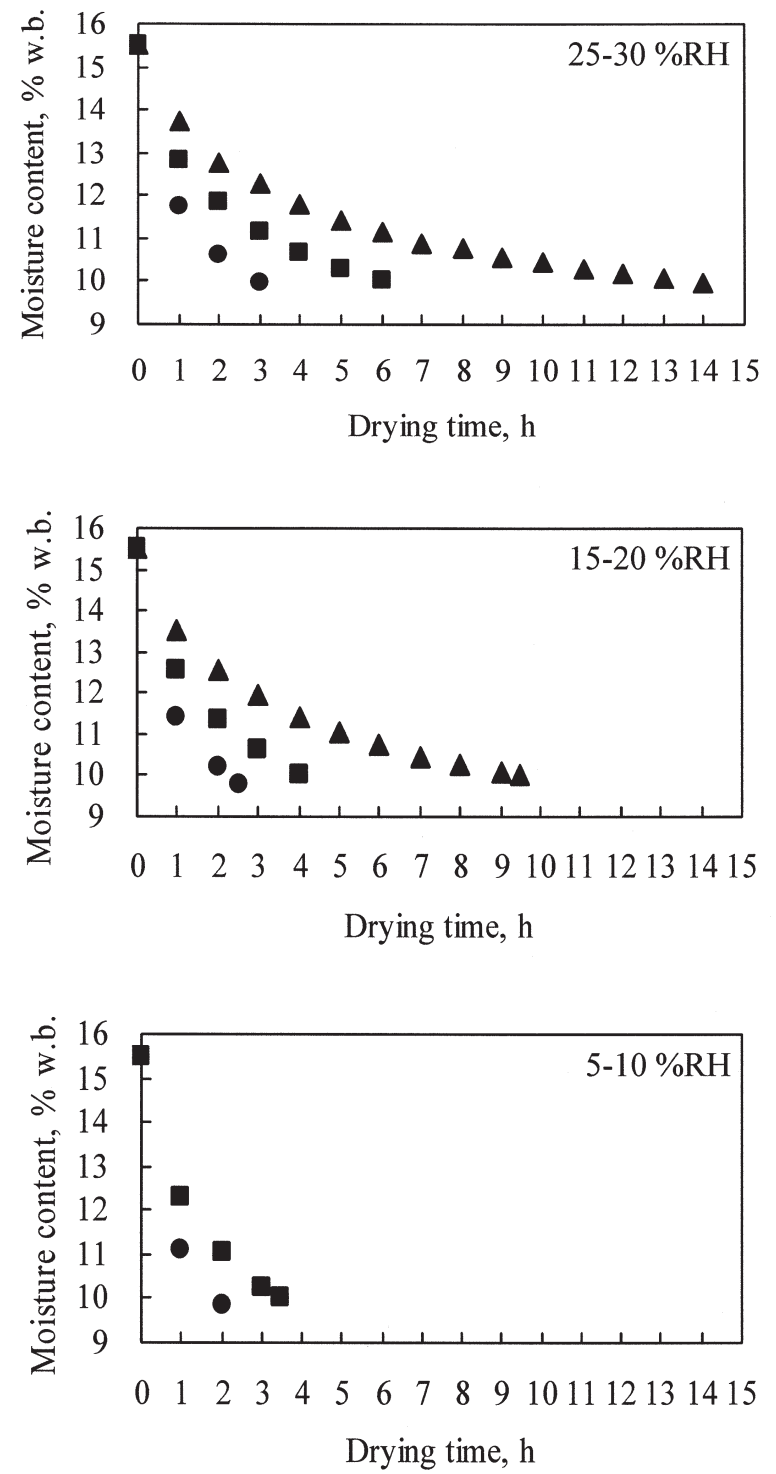

Fig. 5. Changes in moisture content of brown rice in drying process. Symbols of $(\mathbf{O}),(\mathbf{\square})$, and $(\mathbf{\Delta})$ represent the drying temperature of 50,40 , and $30^{\circ} \mathrm{C}$, respectively.

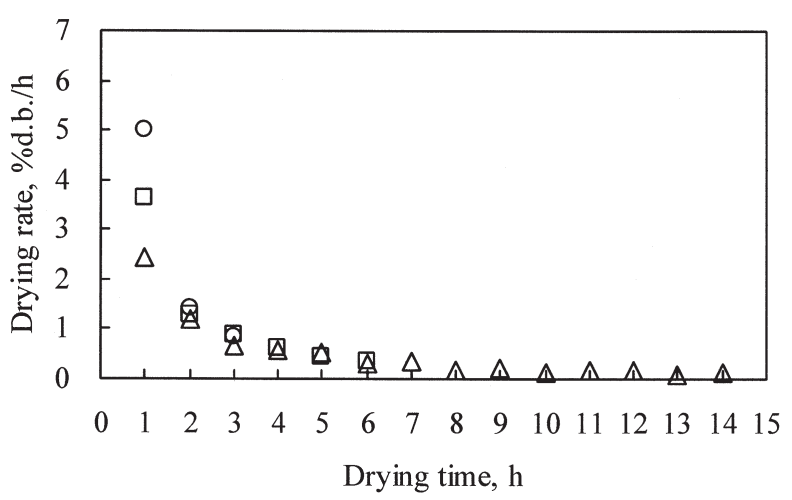

Fig. 6. Effect of drying temperature on drying rate of brown rice. Symbols of $(\bigcirc),(\square)$, and $(\triangle)$ represent the drying temperature of 50,40 , and $30^{\circ} \mathrm{C}$, respectively. (relative humidity : $25-30 \% \mathrm{RH}$ ) was no difference in drying rate after 2 hour. Same results were obtained at 5-10 and $15-20 \% \mathrm{RH}$, and there was no difference of IDR caused by relative humidity (data not shown). It was cleared that the drying temperature affected only IDR without reference to relative humidity.

\section{Effect of drying condition on cracking rate of brown rice}

Figure 7 shows effect of drying condition on cracking rate of the brown rice. The cracking rate of the brown rice dried at $30{ }^{\circ} \mathrm{C}$ was less than $1 \%$, and that of the rice dried at $40{ }^{\circ} \mathrm{C}$ was $2-4 \%$. The brown rice dried at $50{ }^{\circ} \mathrm{C}$ showed $13-15 \%$ of cracking rate. On the other hand, effect of relative humidity on cracking rate was slightly found without reference to drying temperature. Goto et al. (1994) reported that the cracking rate of $72 \%$ was measured on brown rice dried from 20 to $15 \%$ m.c. at $30{ }^{\circ} \mathrm{C}$ and $30 \% \mathrm{RH}$. In this study, brown rice with $15.5 \%$ of initial moisture content was dried at similar drying condition, $30{ }^{\circ} \mathrm{C}$ and $25-30 \% \mathrm{RH}$, but the cracking rate was only less than $1 \%$. These results indicated that the drying of low moisture brown rice have a possibility of reducing cracked rice.

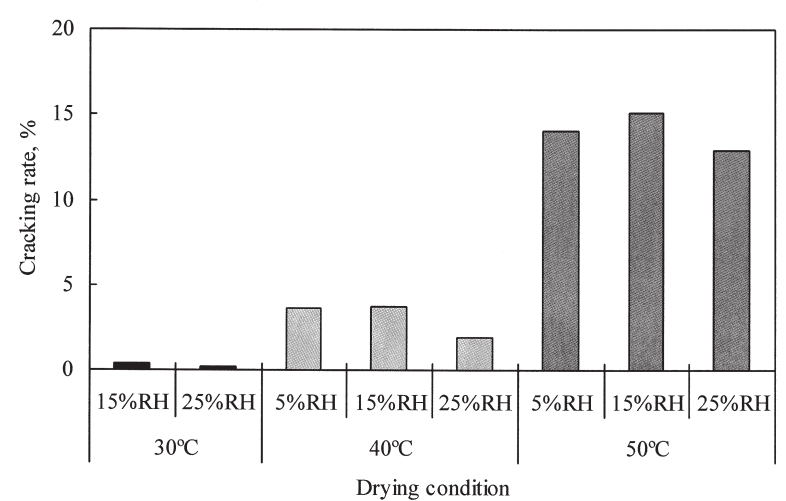

Fig. 7. Effect of drying condition on cracking rate of brown rice with $10.0 \%$ m.c.

\section{Relationship between initial drying rate and cracking rate}

It was reported that cracking rate of brown rice increased proportional to the IDR (Omar et al., 1989; Goto et al., 1994), and a similar relation was found out in our work (Fig. 8.); the cracking rate increased exponentially with the IDR. Goto et al. (1994) concluded that in drying brown rice with $20 \%$ m.c., the IDR of less than $3.5 \%$ d.b./h was required for restricting cracking rate to $5 \%$. On the other hand, the less than $4.5 \%$ d.b./h of IDR suppressed the cracking rate to $5 \%$ in the present work in which the brown rice with $15 \%$ m.c. was dried.

\section{Factors determining IDR}

The drying rate including IDR is decided by drying temperature and relative humidity. The relationship 


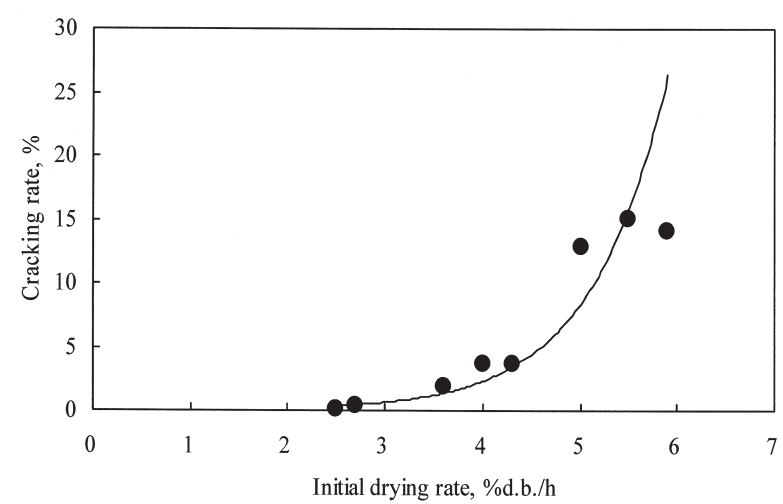

Fig. 8. Relationship between initial drying rate and cracking rate of brown rice.

between IDR is represented by using temperature and relative humidity as Equation (3) by multiple liner regression analysis.

$$
I D R=0.12 T-0.04 H-0.11
$$

where, $T$ is the drying temperature $\left({ }^{\circ} \mathrm{C}\right), H$ is the relative humidity of drying air (\%). In addition, standardized partial regression coefficient of drying temperature and relative humidity were 0.80 and -0.23 , respectively. It means that IDR is affected by drying temperature more than relative humidity. In drying brown rice from 20 to $15 \%$ m.c., the relative humidity affected IDR more than drying temperature (Goto et al., 1994). It was considered that the factors mostly affecting IDR in brown rice drying varies with moisture content of the rice.

\section{Optimal drying condition for brown rice}

In drying operation, it is important to prevent the decrease of germinability and the incidence of cracked rice, because the reduction of the germination rate and increasing of cracking rate are regarded as quality deterioration.

The germinability is one of the most important factors for the quality of the brown rice stored, so that the upper limit of drying temperature should be decided based on the germination rate. From the result of germination rate depressed at between $60^{\circ} \mathrm{C}$ and $70^{\circ} \mathrm{C}$, the permissible drying temperature is defined as $50^{\circ} \mathrm{C}$ considering safety margin of $10^{\circ} \mathrm{C}$. The result of multiple linier regression analysis shows that the control of

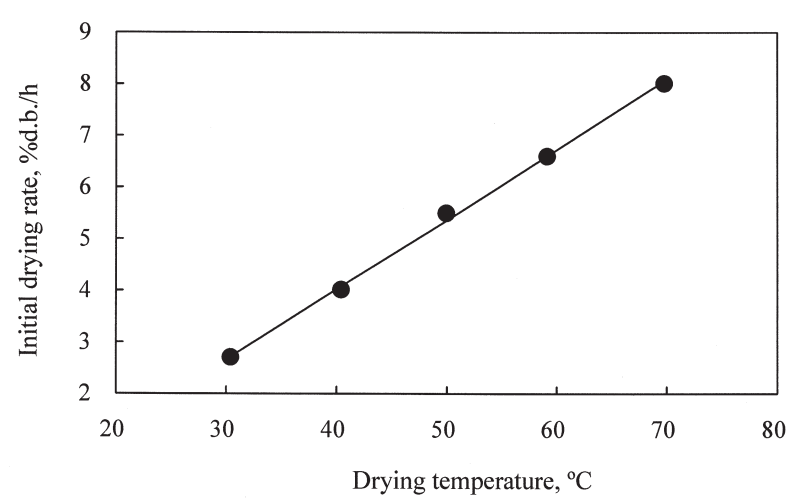

Fig. 9. Relationship between drying temperature and initial drying rate.

drying temperature is more effective on IDR, consequently on cracking rate, than that of relative humidity. For example, to decrease the cracking rate of brown rice to less than $5 \%$, the drying temperature should be less than $45^{\circ} \mathrm{C}$ and this temperature gives less than $4.5 \%$ d.b./h of IDR (Fig. 9.).

From viewing point of inhibiting cracking rate, drying temperature of $40^{\circ} \mathrm{C}$ is preferable, and the drying time at 5-10\% RH was almost same as the drying time at 15-20\% RH (see Fig. 5.) The results from this experiment drew that the optimal drying condition of brown rice to ca. $10 \%$ m.c. is ca. $40{ }^{\circ} \mathrm{C}$ of drying temperature and ca. $5-20 \%$ of relative humidity.

\section{REFERENCES}

Genkawa, T., A. Inoue, D. Hamanaka, T. Uchino 2006 The effect of lowering moisture content on storability of brown rice. Proceedings of $13^{\text {th }}$ world congress of food science \& technology, 331-332

Goto, K., Y. Miwa, J. Liu, K. Tomita 1994 Studies on innovation of brown rice drying (part 1). Journal of the Japanese society of agricultural machinery, 56: 21-26 (in Japanese)

Iwasaki, T., T. Tani 1967 Effect of heating on brown rice composition and quality. Cereal Chemistry, 44(2): 204-210

Omar, S. J., R. Yamashita, K. Goto 1989 New postharvesting method on rice grain (part 2). Journal of the Japanese society of agricultural machinery, 51: 91-95 (in Japanese)

Yamaguchi, S., S. Yamazawa, K. Wakabayashi, K. Horiuchi 1980 Experimental study on the internal stress cracking of rice kernel (part 3). Journal of the Japanese society of agricultural machinery, 43: 397-402 (in Japanese) 